\title{
Application of fuzzy logic in medical data interpretation
}

\author{
U. Dev ${ }^{1 *}$, A. Sultana ${ }^{2}$, D. Saha ${ }^{3}$ and N. K. Mitra ${ }^{4}$ \\ ${ }^{1}$ Department of Mathematics, Edward College, Pabna. \\ ${ }^{2}$ Department of Mathematics, Jahanagirnagar University, Savar, Dhaka. \\ ${ }^{3}$ Department of Biochemistry, Armed Forces Medical College, Dhaka Cantonment, Dhaka. \\ ${ }^{4}$ Faculty of Mathematical \& Physical Sciences, Department of Mathematics, Bangladesh University of Business \\ and Technology, Mirpur, Dhaka
}

\begin{abstract}
This paper serves the purpose of presentation of a general view of the current applications of fuzzy logic in medicine and bioinformatics. Using fuzzy logic, we particularly review medical aspects. We then recall the geometrical interpretation of fuzzy sets as points in a fuzzy hypercube and present two concrete illustrations in medicine (drug addictions) and in bioinformatics (comparison of genomes).
\end{abstract}

Keywords: Drug addictions; Genomes; Bioinformatics; Illness; Sickness, Deal, Inherent; Formalism; Render

\section{Introduction}

The diagnosis of disease involves inherent to medicine and involves several levels of uncertainty and imprecision.

Depending on the patient, a single disease may manifest itself quite differently and with different intensities. A single symptom may correspond to different disease on the other hand; several diseases present in patient may interact and interfere with the usual description of any of the diseases.

Disease entities uses linguistic terms that are also imprecise and vague of the best and most precise description. Moreover, the classical concepts of health and disease are mutually exclusive and opposite. However, some recent approaches consider both concepts as complementary processes in the same continuum (Jobe and Helgason, 1998, Helgason and Jobe 2003, Helgason and Malik et al., 2001, Kosko 1992, Kosko 1993, Sadegh-Zadeh 1999). According to the definition issued by the World Health Organization (WHO), health is a state of complete physical, mental and social well-being, and not merely the absense of disease or infirmity.

The loss of health can be seen in the three forms : disease, illness, and sickness. To deal with imprecision and uncertainty we have at our disposal fuzzy logic. It is partial truth values, between true and false introducing Fuzzy logic.
According to Aristotelian logic, for a given proposition or state we only have two logical values : true- false, blackwhite, 1-0. Things are not either black or white, but most of the times are grey, in real life.

Thus, in many practical situations it is convenient to consider intermediate logical values. Let us show this with a very simple medical example. Consider the statement "You are healthy". Is it true if you have only a broken nail? Is it false if you have a terminal cancer?

Everybody is healthy to some degree $\mathrm{h}$ and ill to some degree $\mathrm{i}$. If you are totally healthy, then of course $\mathrm{h}=1, \mathrm{i}=$ 0 . Usually, everybody has some minor health problems and $\mathrm{h}<1$, but

$$
\mathrm{h}+\mathrm{i}=1 \longrightarrow(1)
$$

In the other extreme situation, $\mathrm{h}=0$ and $\mathrm{i}=1$ so that you are not healthy at all (you are dead). In the case you have only a broken nail, we may write $\mathrm{h}=0.999, \mathrm{i}=0.01$; if you have a painful gastric ulcer, $\mathrm{i}=0.6, \mathrm{~h}=0.4$, but the case you have a terminal cancer probably $\mathrm{i}=0.95, \mathrm{~h}=0.05$. As we will see, this is a particular case of Kosko's hypercube : the one dimensional case (Kosko 1992).

\section{Fuzzy logic in medicine}

The complexity of medical practice makes traditional qualitative approaches of analysis inappropriate. In 
medicine, the lack of information, and its imprecision, and many times, contradictory nature and common facts. The sources of uncertainty can be classified as follows (Abbod et al., 2001).

Information about the patient; Medical history of the patient, which is usually supplied by the patient and/ or his/ her family. This is usually highly subjective and imprecise; Physical examination: The physician usually obtains objective date, but in some cases the boundary between normal and pathological status is not sharp; Laboratory results and other diagnostic tests, but they are also subject to some mistakes and even to improper behavior of the patient prior to the examination; The patient may include simulated, exaggerated, understated symptoms, or may even fail to mention some of them and we stress the paradox of the growing number of mental disorders versus the absence of a natural classification. The classification in critical (i, e, borderline) cases is difficult, particularly when a categorical system of diagnosis is considered.

Fuzzy logic plays an important role in medicine (Abbod et al., 2001) (Barro and Marin 2002, Boegl et al., 2004, Mahfouf et al., 2001, Mordeson et al., 2000, Szczepaniak et al., 2000). Some examples showing that fuzzy logic crosses many disease groups are the following:

To predict the response to treatment with citalopram in alcohol dependence (Naronjo et al., 1997); analyze diabetic neuropathy (Lascio et al., 2002) and to detect early diabetic retinopathy (Zahlm et al., 2000); determine appropriate lithium dosage (Sproule et al., 1997, Stip et al., 2001); calculate volumes of brain tissue from magnetic resonance imaging (MRI) (Brandt et al., 1994) and to analyze functional MRI data (Lu et al., 2003.); characterize stroke subtypes and coexisting causes of ischemic stroke (Jobe and Helgason 1998, Helgason et al., 2001). (Dickerson and Helgason 1997, Helgason and Jobe 1999); improve decision- making in radiation therapy (Papageorgiou et al., 2003); control hypertension during anesthesia (Oshita et al., 1994); determine flexor- tendon repair techniques (Johnson et al., 2001); detect breast cancer (Hassanien AE. 2003), lung cancer (Seker et al., 2003) assist the diagnosis of central nervous systems tumors (astrocytic tumors) (Belacel 2004); visualize nerve fibers in the human brain (Axer et al., 2003); study the auditory P50 component in schizophrenia (Zouridakis et al., 1997) and Many other areas of application, to mention a few, are (a)
(Massad to make decisions in nursing (Im and Chee, 2003); (b) to overcome electro acupuncture accommodation (Zhu et al., 2001).

We used the database MEDLINE to identify the medical publications using fuzzy logic. We used as keywords fuzzy logic and grade of membership. The total number of articles per year appears in Table-I. The data is from 2001 to 2012 and

Table I. Number of Papers per year in medicine using fuzzy logic.

\begin{tabular}{|c|c|}
\hline Year & Number \\
\hline 2000 & 375 \\
\hline 2001 & 76 \\
\hline 2002 & 128 \\
\hline 2003 & 175 \\
\hline 2004 & 186 \\
\hline 2005 & 198 \\
\hline 2006 & 212 \\
\hline 2007 & 208 \\
\hline 2008 & 201 \\
\hline 2009 & 213 \\
\hline 2010 & 223 \\
\hline 2011 & 276 \\
\hline 2012 & 295 \\
\hline
\end{tabular}

includes also the number of those publications in 2000 and before. It is table of 2766 articles and agrees essentially with the numbers indicated. We plan to screen databases in the engineering literature that covers medicine related articles since it is difficult to publish medical results using a fuzzy logic approach. In the future we will compare the figures obtained. 
Fig. 1. indicates an exponential growth in the number of articles in medicine making use of fuzzy technology.

\section{Fuzzy Logic in Bioinformatics}

Fuzzy logic and fuzzy technology are now frequently used in bioinformatics. The following are some examples:

To increase the flexibility of protein motifs (Chang et. al., 2002); study differences between polynucleotide (Torres and Nieto 2003); analyze experimental expression data (Tomida et al., 2002). using fuzzy adaptive resonance theory; align functional and ancestral relationships between protains via fuzzy alignment methods (Blankenbe Cler et. al. 2003), or using a generalized radial basis function neural network architecture that generates fuzzy classification rules (Wang et. al. 2003.); analyze the relationships between genes and decipher a genetic network (Ressom et. al. 2003); process complementary deoxyribonucleic acid (cDNA) microarray images (Lukac et al, 2003). The procedure should be automated due to the large number of spots and it is achieved using a fuzzy vector filtering framework and classify amino acid sequences into different super families (Bandyopadhyay 2005).

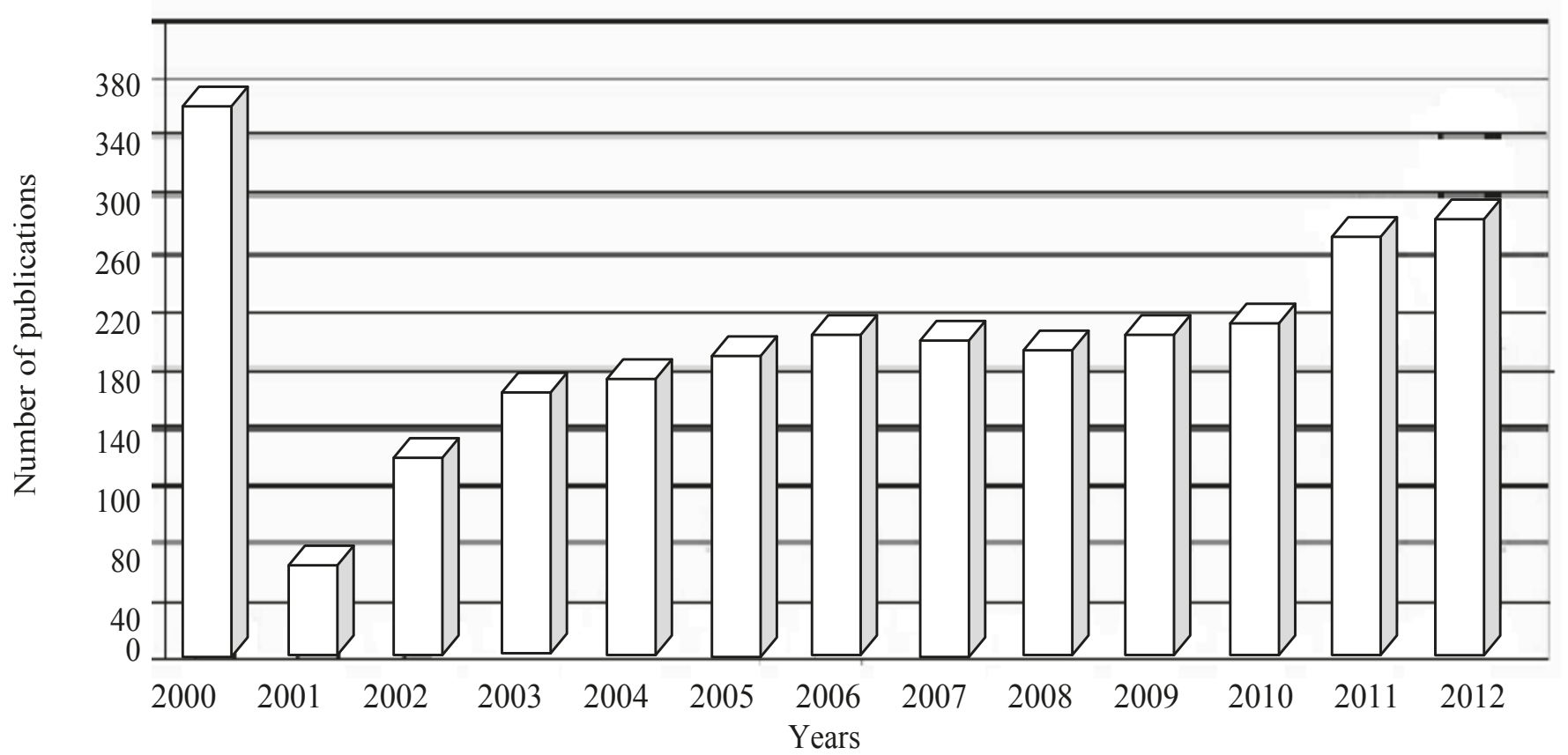

Fig. 1. Number of Publications per year indexed in MEDLINE using fuzzy logic.

sequences based on a fuzzy recast of a dynamic programming algorithm (Schlosshauer and Ohlsson 2002); DNA sequencing using genetic fuzzy systems (Cordon et al., 2004.); cluster genes from microarry data (Belacel et. al., 2009) predict protins subcellular locations from their dipeptide composition (Huang and $\mathrm{Li}, 2004$ ). using fuzzy k-nearest neighbors algorithm; simulate complex traits influenced by genes with fuzzy- valued effects in pedigreed populations (Carleos el al., 2003). attribute cluster membership values to genes (Dembele and Kastner 2003) applying a fuzzy partitioning method, fuzzy C-means; map specific sequence patterns to putative functional classes since evolutionary comparison leads to efficient functional characterization of hypothetical protains (Heger and Holm, 2003). The authors used a fuzzy alignment model; analyze gene expression data (Woolf and Wang 2000). unravel

\section{Fuzzy Hypercube}

In 1992, Kosko (Kosko 1993) introduced a geometrical interpretation of fuzzy sets as points in a hypercube. In 1998, Helgason and Jobe (Jobe and Helgason 1998.) used the unit hypercube to represent concomitant mechanisms in stroke. Indeed, for a given set

$$
X=\left\{x_{1}, x_{1}, \ldots \ldots \ldots \ldots \ldots \ldots . . . x_{n}\right\} \rightarrow(2)
$$

a fuzzy subset is just a mapping

$$
\mu: X \rightarrow \mathrm{I}=[0,1] \rightarrow(3)
$$


and the value $(\mathrm{x})$ expresses the grade of membership of the element to the fuzzy subset .

For example, let $\mathrm{X}$ be the set of persons of some population and let the fuzzy set $\mu$ be defined as healthy subjects. If Jhon is a member of the population (the set X), then, (Rubel) gives the grade of healthiness of Rubel, or the grade of membership of John to the set of healthy subjects. If is the fuzzy set that describes the grade of depression, then (Maya) is the degree of depression of Maya.

Thus, the set of all fuzzy subsets (of $X$ ) is precisely the unit hypercube $\mathrm{I}^{\mathrm{n}}=[0,1]^{\mathrm{n}}$, as any fuzzy subset $\mu$ determines a point $\mathrm{p} \in \mathrm{I}^{\mathrm{n}}$ given by $\mathrm{p}=\mu\left(x_{1}\right), \mu\left(x_{2}\right), \ldots \ldots \ldots \mu\left(x_{n}\right)$ Reciprocally, any point $\mathrm{A}=\left(a_{1}, a_{2}, \ldots \ldots . a_{n}\right) \in \mathrm{I}^{\mathrm{n}}$ generates a fuzzy subset $\mu$ defined by $\mu\left(x_{1}\right)=a_{1}, i=1,2, \ldots \ldots \ldots \ldots, n$.

Nonfuzzy or crisp subsets of $\mathrm{X}$ are given by mappings $\mu: \rightarrow\{0,1)$, and are located at the $2^{\mathrm{n}}$ corners of the n-dimensional unit hypercube $\mathrm{I}^{\mathrm{n}}$. For graphic representations of the two- dimensional and three-dimensional hypercube, we refer (Nieto JJ, Torres A., 2003):

$\mathrm{p}=\left(\mathrm{p}_{1}, \mathrm{p}_{2}, \ldots \ldots \ldots, \mathrm{p}_{\mathrm{n}}\right), \mathrm{q}=\left(\mathrm{q}_{1}, \mathrm{q}_{2}, \ldots \ldots, \mathrm{q}_{\mathrm{n}}\right) \in \mathrm{I}^{\mathrm{n},} \rightarrow(4)$

not both equal to the empty set $\phi(\mathrm{O}, \mathrm{O}, \ldots . . . \mathrm{O})$, we define the difference between $\mathrm{p}$ and $\mathrm{q}$ as

$$
\begin{aligned}
& \mathrm{d}(\mathrm{p}, \mathrm{q})= \\
& \frac{\sum_{i=1}^{n}\left|p_{i}-q_{i}\right|}{\sum_{i=1}^{n} \max \left\{p_{i}, q_{i}\right\}}
\end{aligned}
$$

Of course . We know that $\mathrm{d}$ is indeed a metric (Nieto and Torres A. et al., 2003), Hypercubical calculus has been described in (Zaus 1999), while some biomedical applications of the fuzzy unit hypercube has been utilized to study differences between polynucleotides (Nieto and Torres 2003) and to compare genomes (Torres and Nieto, 2003, Nieto et al., 2003).

\section{An application to drug addictions}

We now present an example of the use of the fuzzy hypercube in a medical case of consumption of drugs.

We now present an example of the use of the fuzzy hypercube in a medical case of consumption of drugs.

Consider the following fuzzy variables : Smoking and alcohol drinking. If you do not smoke, then your degree of being a smoker is evidently 0 . If you smoke, for example, six cigarettes per day, we say that your degree of being a smoker is 0.8 . If the consumption is ten or more, the degree is 1. See (Kasabov et al., 1996). for a geometrical representation of the fuzzy concept of being a smoker.

With respect to the other fuzzy variable, if you drink no alcohol, the degree of this variable is 0 . If you drink more than $75 \mathrm{cc}$ of alcohol per day, the degree of alcoholism is 1 . For $25 \mathrm{cc} / \mathrm{d}$, the degree could be 0.4 and for $50 \mathrm{cc} / \mathrm{d}, 0.8$.

Thus, the fuzzy set $\mu=(0,0)$ corresponds to a nonsmoker and teetotaler. Some further examples are the following : the set $\mu=(1,0)$ represents a heavy smoker, but a teetotaler, and the set $\mu=(0.8,1)$ is a person who smokes about six cigarettes a day and is a risk consumer of alcohol.

Suppose you correspond to the fuzzy set $\lambda=(1,1)$, have recently had some health problems, and your physician has advised you to reduce your consumption of cigarettes and alcohol by half. The ideal situation for your health is, of course, the point $\mu=(0,0)$, but it is possible difficult to achieve.

Cigarette smoking and alcohol drinking during adolescence have been shown to be associated with a greater possibility of concurrent and future substance-related disorders (Lewinsohn P., et al., 1999) and (Nelson and Wittchen 1998).

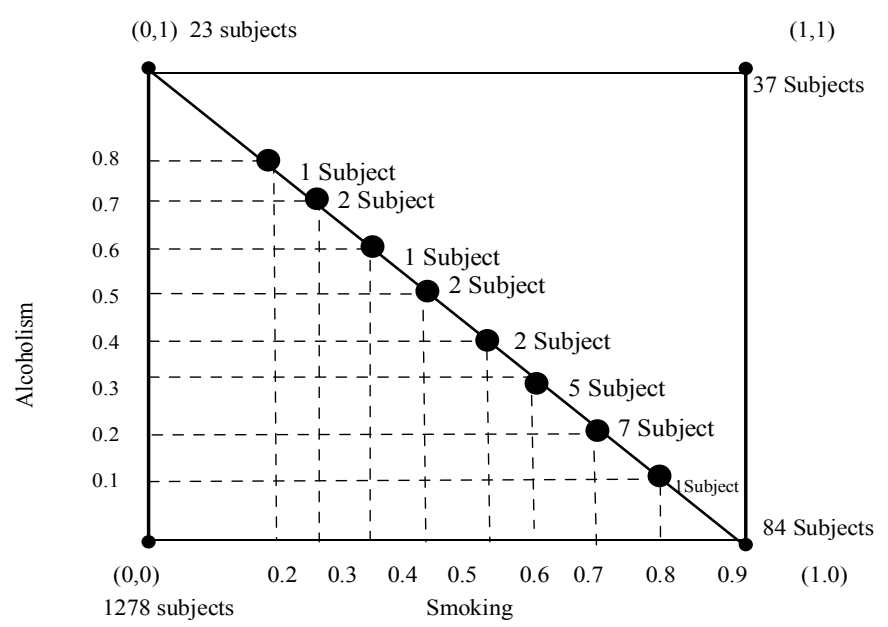

Fig. 2. Number of subjects in the two- dimensional fuzzy hypercube $I^{2}$. 
In order to report patterns of drug use and to describe factors associated with substance use in adolescents, a cross- sectional survey was carried out in a representative population sample of 2550 adolescents, aged 12 to 17 years, from Galicia (an autonomous region located in the Northwest of Spain). The original survey covered the use of alcohol, tobacco, illicit drugs, and other psychoactive substances. For tobacco smoking and alcohol drinking, each subject of the population sample was assigned a fuzzy degree of addiction (risk use) and mapped into the twodimensional hypercube $\mathrm{I}^{2}$ by an expert.

Several subjects occupy the same point in the two-dimensional hypercube. For example Figure- 2 represents the number of subjects in the cross- sectional survey according to the two fuzzy degrees of addiction.

The reader can see that there are 1278 subjects corresponding to the point $(0,0)$, that is, nonsmoker and teetotalor. Also 7 adolescents are at the point $(0.8,0.2)$. There are 121 subjects on the line of probability

$$
x_{1}+x_{2}=1
$$

Indeed (See Fig. 2.), $23+1+1+2+2+7+1+84=121$.

Most subjects were inside the hypercube but outside the line of probability. This means that the vast majority of subjects $(2429 / 2550 \approx 95.25 \%)$ are outside the line of probability. This is in agreement with the fundamental limitation of probability theory with respect to clinical science in general (Jobe and Helgason 1998) and agrees with its results $(29 / 30 \approx 6.66 \%)$.

We refer to (Nieto and Torres 2003), for details on the general theory of fuzzy midpoints and their applications. It has been used recently to average biopolymers (Casasnovas and Rossello 2005).

\section{An application to the comparison of genomes}

Definition: Nitrogenous Base: In nitrogenous base, there are two elements i, e, DNA ( $\rightarrow$ Thianine, $\mathrm{C} \rightarrow$ Cytosine, $\mathrm{A}$ $\rightarrow$ Adenine, $\mathrm{G} \rightarrow$ Guanine $)$ and RNA $(\mathrm{A} \rightarrow$ Adenine, $\mathrm{G} \rightarrow$ Guanine, $\mathrm{C} \rightarrow$ Cytosine, $\mathrm{U} \rightarrow$ Uracil).

Definition: Nucleotide: Nucleotide is made by three components i, e, Base, Sugar, and phosphate.

Definition: Codon: The correspondence between specific DNA base sequence, and the amino acids they specify called genetic code. Each nucleotide triplet is called a codon. A codon is made by three letters.

Whole genome sequence comparison is important in bioinformatics (Torres and Nieto 2003, Castelli at. al. 2004).

The complete genome sequence of Mycobacterium tuberculosis $\mathrm{H} 37 \mathrm{Rv}$ is available at http://www.ncbi.nlm.nih.gov with accession number NC_000962.

The genome comprises 4411529 base pairs, contains around 4000 genes, and has a very high guanine+cytosine content (Cole et al., 1998).

Table II. Number of nucleotides at the three base sites of a codon in the coding sequence of Mycobacterium tuberculosis.

\begin{tabular}{lllll}
\hline \multicolumn{1}{c}{ T } & C & A & G & \\
\hline First base & 216051 & 409011 & 228244 & 470868 \\
Second base & 269638 & 416457 & 233472 & 404607 \\
Third base & 217803 & 458256 & 210892 & 437223 \\
\hline
\end{tabular}

Table III. Fractions of nucleotides at the three base sites of a codon in the coding sequence of Mycobacterium tuberculosis. (Multiplying the above numbers by $7.54 \times 10^{-7}$, where $\mathrm{PH}=$ 7.54 and $\mathrm{PH}$ of $\mathrm{H}_{2} \mathrm{O}=10^{-7}$ ).

\begin{tabular}{lllll}
\hline \multicolumn{1}{c}{ T } & C & A & G & \\
\hline First base & 0.1632 & 0.3089 & 0.1724 & 0.3556 \\
Second base & 0.2036 & 0.3145 & 0.1763 & 0.3056 \\
Third base & 0.1645 & 0.3461 & 0.1593 & 0.3302 \\
\hline
\end{tabular}

Table IV. Number of nucleotides at the three base sites of a codon in the coding sequence of Aquifex aeolicus.

\begin{tabular}{lllll}
\hline \multicolumn{1}{c}{ T } & C & A & G & \\
\hline First base & 82722 & 77800 & 157096 & 167050 \\
Second base & 159068 & 84092 & 168591 & 72917 \\
Third base & 103692 & 119016 & 147956 & 114004 \\
\hline
\end{tabular}


Table V. Fractions of nucleotides at the three base sites of a codon in the coding sequence of Aquifex aeolicus. (According to above method).

\begin{tabular}{lllll}
\hline \multicolumn{1}{c}{ T } & C & A & G & \\
\hline First base & 0.1706 & 0.1605 & 0.3241 & 0.3446 \\
Second base & 0.3282 & 0.1735 & 0.3478 & 0.1504 \\
Third base & 0.2139 & 0.2455 & 0.3052 & 0.2352 \\
\hline
\end{tabular}

Computing (Torres and Nieto 2003) the number of the nucleotides at the three base sites of a codon in the coding sequences of M. tuberculosis (Table II.), and then calculating the corresponding fractions, we have the fuzzy set of frequencies of the genome sequence of $M$. tuberculosis (Table III.).

This set can be considered as a point in the hypercube $\mathrm{I}^{12}$. Indeed, the point

(0.1632, 0.3089, 0.1724, 0.3556, 0.2036, 0.3145, 0.1763, $0.3056,0.1645,0.3461,0.1593,0.3302) \in \mathrm{I}^{12} . \rightarrow(6)$

Aquifex aeolicus was one of the earliest diverging, and is one of the most thermophilic, bacteria known (Deckert et al., 1998). It can grow on hydrogen, oxygen, carbondioxide and mineral salts. The complex metabolic machinery needed for A. aeolicus to function as a chemolithoautotroph (an organism which uses an inorganic carbon source for biosynthesis and an inorganic chemical energy source) is encoded within a genome that is only $1 / 3$ the size of the E.coli genome.

The corresponding data for A. aeolicus was obtained from http://www.ncbi.nih.gov with accession number NC_000918, and is presented in Table 4 and 5, respectively. The complete genome sequence has 1551335 base pairs. The fuzzy set of frequencies of the genome of A. aeolicus is

(0.1706, 0.1605, 0.3241, 0.3446, 0.3282, 0.1735, 0.3478, $0.1504,0.2139,0.2455,0.3052,0.2352) . \in \mathrm{I}^{12} . \rightarrow(7)$

Using the distance given in (5), it is possible to compute the distance between these two fuzzy sets representing the frequencies of the nucleotides of A. aeolicus and M.tuberculosis :

$\mathrm{d}($ A. aeolicus, M. tuberculosis $)=\frac{2.2125}{6.106} \approx 0.3623 \rightarrow(8)$
In (Torres and Nieto 2003.), we calculate the difference between M. tuberculosis and E. Coli K-12 obtaining

$\mathrm{d}($ M. tuberculosis, E. coli $)=\frac{0.8506}{3.4253} \approx 0.2483 \rightarrow(9)$

Using the corresponding data for E.coli, (Torres and Nieto 2003),

we get,

$\mathrm{d}($ A. aeolicus, E. coli $)=\frac{0.8514}{5.0161} \approx 0.1697 \rightarrow(10)$

\section{Conclusion}

The complexity of medical practice makes traditional quantitative approaches of analysis inappropriate. In medicine the lack of information, and its imprecision, and many times contradictory nature are common facts. We classified the sources of these uncertainty. Thus fuzzy logic plays an important role in medicine. We indicate on exponential growth in the number of articles in medicine making use of fuzzy technology.

Bioinformatics derives Knowledge from computer analysis of biological data. This data can consist of the information stored in the genetic code, and also experimental results from various sources, patient statistics, and scientific literature. We discussed fuzzy logic and fuzzy technology are now frequently used in bioinformatics.

The researcher introduced a geometrical interpretation of fuzzy sets as points in a hypercube. Recently, the fuzzy hypercube has been utilized to study differences between polynucleotide and to compare genomes.

We present the use of the fuzzy hypercube in a medical case of consumption of drugs. We refer to details on the general theory of fuzzy midpoints and their applications. It has been used recently to average biopolymers.

Whole genome sequence comparison is important in bioinformatics. Using the distance given in (5), it is possible to compute the distance between these two fuzzy sets representing the frequencies of the nucleotides.

In both case, either drug addiction or comparison of genomes, we find out the result in fuzzy values.

Smoking and alcohol drinking are very effected harmfully to a subjects health. Mycobacterium 
Tuberculosis, Aquifex Aeolicus, and Escherichia coli are very harmful to a patient. In this paper, we study using fuzzy logic about such kind of these drug and genomes which are important for the expert and statistical purpose in the various part of health and diagnosis.

\section{References}

Abbod MF, von Keyserlingk DG, Linkens DA, Mahfouf M. (2001), Survey of utilisation of fuzzy technology in Medicine and Healthcare, Fuzzy Sets and Systems. 120(2): 331-349.

Axer H, Jantzen J, Keyserlingk DG, Berks G, (2003), The application fuzzy-based methods to central never fiber imaging. Artificial Interlligence in Medicine. 29(3): 225-239.

Barro S and Marin R. (2002), Fuzzy Logic in Medicine. Heidelberg, Germany: Physica.

Boegl K, Adlassnig KP, Hayashi Y, Rothenfluh TE, Leitich H. (2004), Knowledge acquisition in the fuzzy knowledge reorientation framework of a medical consultation system. Arificial Intelligence in Medicine. 30(1): 1-26.

Brandt MF, Bohan TP, Kramer LA, Fletcher JM. (1994), Estimation of CSF, white and gray matter volumes in hydrocephalic children using fuzzy clustering of MR images. Computerized Medical Imaging and Graphics. 18(1): 25-34.

Bourbakis NG. (2003), Bio-imaging and bio-informatics. IEEE Transactions on Systems, Man and Cybernetics, Part B: Cybernetics. 33(5): 726-727.

Belacel N, Cuperlovic- Culf M, Laflamme M, Ouellette R. (2004), Fuzzy J-Means and VNS methods for clustering genes from microarray data. Bioinformatics. 20(11): 1690-1701.

Blankenbecler R, Ohlsson M, Peterson C, Rigner M. (2003), Matching protein structures with fuzzy alignments. Proceedings of the National Academy of Sciences of the United States of America. 100(21): 11936-11940.

Bandyopadhyay S. (2005), An efficient technique for superfamily classification of amino acid sequences: feature extraction, fuzzy clustering and prototype selection. Fuzzy Sets and Systems. 152(1): 5-16.
Cordon O, Gomide F, Herrera F, Hoffmann F, Magdalena L. (2004), The years of genetic fuzzy systems: current framework and new trends. Fuzzy Sets and Systems. 141(1): 5-31.

Carleos C, Rodriguez F, Lamelas H, Baro JA. (2003), Simulating complex traits influenced by genes with fuzzy- valued effects in pedigreed populations. Bioinformatics. 19(1): 144- 148.

Casasnovas J and Rossello F. (2005), Averaging fuzzy biopolymers. Fuzzy Sets and Systems. 152(1): 139-158.

Castelli V, Aury JM, Jaillon O, Wincker P, Clepet C, Menard M, Salanoubat M. (2004), Whole genome sequence comparisons and "full-length" cDNA Sequences: a combined approach to evaluate and improve Arabidopsis genome annotation. Genome Research. 14(3): 406-413.

Cole ST, Brosch R, Parkhill J, Garnier T, Churcher C, Harris D, Barrell BG (1998), Deciphering the biology of Mycobacterium tuberculosis from the complete genome sequence. Nature. 393(6685): 537-544.

Chang BC, Halgamuge SK. (2002), Protein motif extraction with neuro-fuzzy optimization. Bioinformatics. 18(8): 1084-1090.

Dickerson JA and Helgason CM. (1997), The characterization of stroke subtype and science of evidence-based medicine using fuzzy logic. Journal of Neurovascular Disease. 2(4): 138-144.

Dembele D and Kastner P. (2003), Fuzzy C-means method for clustering microarry data. Bioinformatics. 19(8): 973-980.

Deckert G, Warren PV, Gaasterland T, Young WG, Lenox AL, Graham DE Swanson RV (1998), The complete genome of the hyperthermophilic bacterium Aquifex aeolicus. Nature. 392(6674): 353-358.

Fuchs. R. (2002), From sequence to biology: the impact on bioinformatics. Bioinformatics. 18(4): 505-506.

Helgason CM, Jobe TH. (2003), Perception- base reasoning and fuzzy cardinality provide direct measures of causality sensitive to initial conditions in the individual patient (:Invited paper). International Journal of Computational Cognition. 1(2): 70-104. 
Helgason CM, Malik DS, Cheng S-C, Jobe TH., Mordeson JN. (2001), Statistical versus fuzzy of variable interaction in patients with stroke. Neuroepidemiology. 20(2): 77-84

Helgason CM. Jobe TH. (1999), Causal interactions, fuzzy sets and cerebrovascular "accident": the limits of evidence-based medicine and the advent of complexity- based medicine. Nellroepidemiology. 18(2): 64-74.

Hassanien AE. (2003), Intelligent data analysis of breast cancer based on rough set theory. International Journal on Artificial Intelligence Tools. 12(4): 465-479.

Huang Y and Li Y. (2004), Prediction of protein subcellular locations using fuzzy k-NN method. Bioniformatics. 20(1): 21-28.

Heger A and Holm L. (2003), Sepsitive pattern discovery with 'fuzzy' alignaments of distantly related proteins. Bioinformatics. 19(suppl 1):i 130-i137.

Im EO and Chee W. (2003), Fuzzy logic and nursing. Nursing Philosophy. 4(1): 53-60.

Jobe TH and Helgason CM. (1998), The fuzzy cube and causal efficacy : representation of concomitant mechanisms in stroke. Neural Networks. 11(3): 549-555.

Johnson M, Firoozbakhsh K, Moniem M, Jamshidi M. (2001), De-termining flexor-tendon repair techniques via soft computing IEEE Engineering in Medicine and Biology Manazine. 20(6): 176-183.

Kosko B. (1992), Neural Networks and Fuzzy Systems. Englewood. Cliffs, NJ: Prentice- Hall.

Kosko B. (1993), Fuzzy Thinking : The New Science of Fuzzy Logic. New York, NY: Hyperion Press.
Kulikova T, Aldebert P, Althorpe N, et al., (2004), The EMBL nucleotide sequence database. Nucleic Acids Research. 32(database issue): D27-D30.

Kasabov NK. (1996), Foundations of Neural Networks, Fuzzy Systems and Knowledge Engineering. Cambridge, Mass: MIT Press.

Lu Y, Jiang T, Zang Y. (2003), Region growing method for the analysis of functional MRI data. Neurolmage, 20(1): 455-465.

Lukac R, Plataniotis KN, Smolka B, Venetsanopoulos AN. (2005), cDNA microarray image processing using fuzzy vector filtering framework. Fuzzy Sets and Systems. 152(1): 17-35.

Lewinsohn PM, Rohde P, Brown RA. (1999), Level of current and past adolescent cigarette smoking as predictors of future substance use disorders in young adulthood. Addiction. 94(6): 913-921.

Lascio LD. Gisolfi A, Albunia A, Galardi G, Meschi F. (2002), A fuzzy based methodology for the analysis of diabetic neuropathy. Fuzzy Sets and Systems. 129(2): 203-228.

Marchais P. (2002), De I'esprit et des modes de classification en psychiatric (Classification in psychiatry: principles, modes and ways of thinking). Annales Medico-Psychologiques. 160(3): 247-252.

Mahfouf M, Abbod MF, Linkens DA. (2001), A survey of fuzzy logic monitoring and control utilisation in medicine. Artificial In-telligence in Medicine. 21(1-3): 27-42.

Mordeson JN, Malik DS, Cheng S-C. (2000), Fuzzy Mathematics in Medicine. Heidelberg, Germany: Physica.

Matt GE, Turingan MR, Dinh QT, Felsch JA, Hovell MF, Gehrman C. (2003), Improving self-reports of drug-use: numeric estimates as fuzzy sets. Addiction. 98(9): 1239-1247. 
Massad E, Ortega NR, Struchiner CJ, Burattini MN. (2003), Fuzzy epidemics. Artificial Intelligence in Medicine. 29(3): 241-259.

Naranjo CA, Bremner KE, Bazoon M, Turksen IB. (1997), Using fuzzy logic to predict response to citalopram in alcohol dependence. Clinical Pharmcology and Therapeutics. 62(2): 209-224.

Nieto JJ and Torres A. (2003), Midpoints for fuzzy sets and their application in medicine. 27(1): 81-101.

Nieto JJ, Torres A, Vazquez- Trasande MM. (2003), A metric space to study differences between polynucleotides, Applied Mathematics Letters. 16(8): 1289-1294.

Nieto JJ, Torres A, Georgiou DN, Karakasidis T. Fuzzy polynucleotide spaces and metrics. to appear in Bulletin of Mathematical Biology.

Nelson CB and Wittchen HU. (1998), DSM-IV alcohol disorders in a general population sample of adolescents and young adults. Addiction. 93(7): 1065-1077.

Oshita S, Nakakimura K, Sakabe T. (1994), Hypertension control during anesthesia. Fuzzy logic regulation of nicardipine in-fusion IEEE Engineering in Medicine and Biology Magazine. 13(5): 667-670.

Papageorgiou EI, Stylios CD, Groumpos PP. (2003), An integrated two-level hierarchical system for decision making in radiation therapy based on fuzzy cognitive maps. IEEE Transactions on Biomedical Engineering 50(12): 1326-1339.

Ressom H, Reynolds R, Varghese RS. (2003), Increasing the efficiency of fuzzy logic-based gene expression data analysis. Physiological Genomics. 13(2): 107-117.

Sadegh-Zadeh K. (1999), Fundamentals of clinical methodology: 3. Nosology. Artificial Intelligence in Medicine. 17(1): 87-108.

Szczepaniak PS, Lisoba PJG, Kacprzyk J. (2000), Fuzzy Systems in Medicine. Heidelberg, Germany; Physica.
Sproule BA, Bazoon M, Shuman KI, Turksen IB, Naranjo CA. (1997), Fuzzy logic pharmacokinetic modeling: application to lithium concentration prediction. Clinical Pharmacology and Therapeutics. 62(1): 29-40.

Stip E, Dufresne J. Boulerice B. Elie R. (2001), Accuracy of the Pepin method to determine appropriate lithium dosages in healthy volunteers. Journal of Psychiatry \& Neuroscience. 26(4): 330-335.

Seker H, Odetayo MO, Petrovic D, Naguib RN. (2003), A fuzzy logic based-method for prognostic decision making in breast and prostate cancers. IEEE Transactions on Information Technology in Biomedicine. 7(2): 114-122.

Schlosshauer M, Ohlsson M and (2002), A novel approach to local reliability of sequence alignments. Bioinformatics. 18(6): 847-854.

Torres A and Nieto JJ. (2004), Fuzzy logic and technology in medicine and psychiatry. preprint.

Torres A and Nieto JJ. (2003), The fuzzy polynucleotide space: basic properties. Bioniformatics. 19(5): 587-592.

Tomida S, Hanai T, Honda H, Kobayashi T. (2002), Analysis of expression profile using fuzzy adaptive resonance theory. Bioinformatics. 18(8): 1073-1083.

Valencia A. (2002), Bioinformatics: biology by other means. Bioinformatics. 18(12): 1551-1552.

Woolf PJ and Wang Y. (2000), A fuzzy logic approach to analyzing gene expression data. Physiological Genomics. 3(1): 9-15.

Wang DH, Lee NK, Dillon TS. (2003), Extraction and optimization of fuzzy protein sequence classification rules using GRBF neural networks. Neural Information Processing- Letters and Reviews. 1(1): 53-59.

Zourdakis G, Boutros NN, Jansen BH. (1997), A fuzzy clustering approach to study the auditory P50 component in schizophrenia. Psychiatry Research. 69(2-3): 169-181. 
Zhu QM, Sun XW, Pipe AG. (2001), A fuzzy controller to overcome EA accommodation, In: Proceedings of IFAC conference on new technologies for computer control. Hong Kong, China. 493-498.

Zahlmann G, Kochner B, Ugi I, Schuhmann D, Liesenfeld B, Wegner A, Mertz M (2000), Hybrid fuzzy image processing for situation assessment. IEEE Engineering in Medicine and Biology Manazine. 19(1): 76-83.
Zaus M. (1999), Crisp and Soft Computing With Hypercubical Calculus. Heidelberg, Germany: Physica.

Received: 25 September 2012; Revised: 13 April 2014; Accepted: 25 August 2014. 